\title{
MANAGEMENT OF COMPLEX FISTULA IN ANO WITH FISTULOTOMY AND STAGE PROCEDURE
}

\author{
MASUM MNH ${ }^{1}$, YAZDANI A ${ }^{2}$, MASUM M ${ }^{3}$, BISWAS MS ${ }^{4}$, BHUIYAN MA ${ }^{5}$, SAHA H ${ }^{6}$
}

\begin{abstract}
:
Background: Complex fistula in ano is a troublesome disease and is difficult to treat. Complex fistula in ano occurs in various forms like multiple external and/or internal openings, internal opening above the dentate line, external opening far away from anal verge, anterior tract etc. They are almost invariably recurrent and frequently associated with other systemic diseases like tuberculosis, inflammatory bowel disease, malignancy etc. A complex fistula in ano has various modalities of treatments like application of setons, fistulotomy or fistulectomy, endorectal advancement flap, anocutaneous advancement flap, fistula plug, fibrin glue, electrocauterization of tract/laser and ligation of intersphincteric fistula tract (LIFT).
\end{abstract}

Objective: The purpose of the study is to evaluate the outcome of complex fistula in ano by fistulotomy and staged procedure.

Methods: The study was held in Dhaka medical college Hospital and various private hospitals located in Dhaka and Brahmonbaria within duration of 8 years (from January, 2011 to January, 2018). Among 256 patients (221 male, 35 female) with median age 48 years (30 to 72 years) with the diagnosis of complex fistula in ano, 135 underwent fistulotomy with application of Seton with stage procedure. 121 patients underwent single stage fistulotomy. 158 patients had history of previous operations. After stage procedure, regular follow up was done every week until wound healing occurred.

Result: Among 256 patients 121 patients (47\%) underwent single stage, 133 (52\%) patients underwent two stage and 2 patients underwent three stage procedure during the trial period. Majority of the patients had minor incontinence; that is flatus and/or loose stool incontinence. But they only persisted for an average of 10 to 16 days and subsided spontaneously. None of the patient had any major (solid stool) incontinence. 4 patients (2\%) had recurrence of fistula on an average of 3-6 months after complete healing. Recurrence occurred in the form of abscess, automatically burst internally, recurrent fistula.2 patients developed bleeding after single stage procedure and was managed by cauterization.

Conclusion: With adequate postoperative care and regular follow up, application of Seton with 'staged procedure' in cases of complex fistula in ano is very effective and has very minimal complications. Chance of major incontinence and recurrence is also less.

Key words: complex fistula in ano, Seton application, stage procedure

J Dhaka Med Coll. 2018; 27(1) : 83-87

\section{Introduction}

Fistulas are commonly divided into: submucosal, inter-sphincteric, transsphincteric (high or low with less of $30 \%$ of external sphincter involvement), supra-sphincteric and extrasphincteric. Treatment options of fistula- in-ano include fistulotomy, seton placement, endorectal advancement flap, fistula plug, fibrin injection and ligation of the intersphincterictract (LIFT). The term complex fistula is modification of the Park's classification, which falls in any one of these conditions, that is,

1. Associate Professor, Department of Surgery, Dhaka Medical College Hospital.

2. Honorary Medical officer, Department of surgery, Dhaka Medical College Hospital.

3. Indoor Medical Officer, Department of Surgery, Dhaka Medical College Hospital.

4. Resident, Department of Surgery, Dhaka Medical College Hospital.

5. Indoor Medical Officer, Department of Surgery, Dhaka Medical College Hospital

6. Dr. Haridas Saha, Assistant Professor, Deprtment of Surgery, Dhaka Medical College, Dhaka

Correspondence : Dr. Md. Nazmul Hoque Masum, Associate Professor, Department of Surgery, Dhaka Medical College Hospital.

Received: 21 July 2017

Revision: 01 September 2017

Accepted: 15 September 2017

DOI: $h t t p: / / d x . d o i . o r g / 10.3329 / j d m c . v 27 i 1.38952$ 
recurrent fistula in ano, multiple external openings, external opening far away from anal verge (the track crosses $>30 \%$ to $50 \%$ of the external sphincter), internal opening above the dentate line, anterior in females, multiple tracks, or the patient has preexisting incontinence, local irradiation, Crohn's disease, malignancy, tuberculosis ${ }^{1-3}$. Due to the involvement of the anal sphincter, the treatment of complex fistula poses a high risk for impairment of continence ${ }^{4,5}$. As there is no single appropriate technique for the treatment of fistula-in-ano, treatment must be navigated by the surgeon's experience and judgment. The surgeon has to keep in mind the tradeoff between the extent of sphincter division, postoperative healing rate, and functional loss ${ }^{4}$. Whatever the type and the extent of fistula are, the principles of anal fistula surgery are to get rid of the fistula, prevent recurrence, and preserve sphincter function. Most of the fistulain-ano has been conventionally treated by either fistulotomy, or fistulectomy, which have been proven to be effective ${ }^{6}$.

Seton is any string-like material which when tied through the fistula tract causes an inflammatory reaction which stimulates fibrosis that fixes and prevents retraction of the sphincter continuity when it is divided. In this way, it maintains sphincter continuity during cutting process ${ }^{7}$. Different types of setons are used for this purpose like silastic tube, silk, linen, braided silk, rubber band, braided polyester, vascular loop, polypropylene, nylon, cable tie, and so forth ${ }^{7}$. In this study, silk has been used in all the patients as seton.

This prospective study investigated the complications and recurrence rate of staged fistulotomy for complex anal fistula.

\section{Patients and Methods}

The present cohort study included 256 patients presenting with complex anal fistula who were managed with fistulotomy from January 2011 to January 2018 in different private clinics of Dhaka and Brahmanbaria. Among 256 patients, 221 were male and 35 were female. All the patients with complex fistula-in-ano with age ranging from 11 to 72 years (mean $+\mathrm{SD}=$
$41.5+11.2)$ were included in this study. Among them 156 were recurrent cases, 83 had history of perianal abscess, 75 were diabetic. 2 patients were of minor age group of below 18 years. Most of the patients $(n=178)$ were between 30-50 years age group. Patients who did not give consent, who had associated other perianal diseases, patients on chemotherapy, radiotherapy were excluded from the study.

When patients were seen in the clinic, they were counseled about the methods of dealing with the fistula and the fact that healing and convalescence is likely to be prolonged. Preoperative assessment included documentation of symptoms, rectal examination, proctoscopy to exclude other pathology of anus and rectum. Rectal preparation was done in all patients by enema in the morning of the day of the surgery. All the patients preferred to have spinal anesthesia. Patients were discharged home after 1 or 2 days of operation. Each patient was assessed weekly until wound healing occurred.

In the operation room, the patients were evaluated in the lithotomy position. Examination under anaesthesia by gentle insertion of probe and/or injecting $\mathrm{H}_{2} \mathrm{O}_{2}$, then methylene blue dye to identify the tract was done prior to operative procedure. External opening of fistula \&skin, subcutaneous tissue along with fistula tract up to internal opening was partially excised.Silk (n-2) was passed through the tract and external and internal sphincters were tightened.Resected specimen was sent for histological examination.

During discharge, patients were advised to take regular dressing by povidon iodine mixed with normal saline twice daily until healing and were encouraged to walk and resume their jobs at their workplaces.

133 patients underwent two stage procedure and second stage was done after 2-3weeks of first stage. 2 patients required third stage as healing was delayed and complications aroused. Patients required three stage procedure were given prolene as cutting seton. During each stage fistula tract was cut lay open. Third stage was done after 2 months of second stage for both the patients. 
121 patients (112 male, 9 female) had lowvariety complex fistula in-ano and they all underwent single stage fistulotomy.

Follow-up was given weekly in each patients as out-patient service. In each follow-up, patients were asked about complications, rectal examination was done, unhealthy tissues were curetted.

\section{Result}

Among 256 patients 121 patients (47\%) underwent single stage, $133(52 \%)$ patients underwent two stage and 2 patients underwent three stage procedure during the trial period (Figure 1).

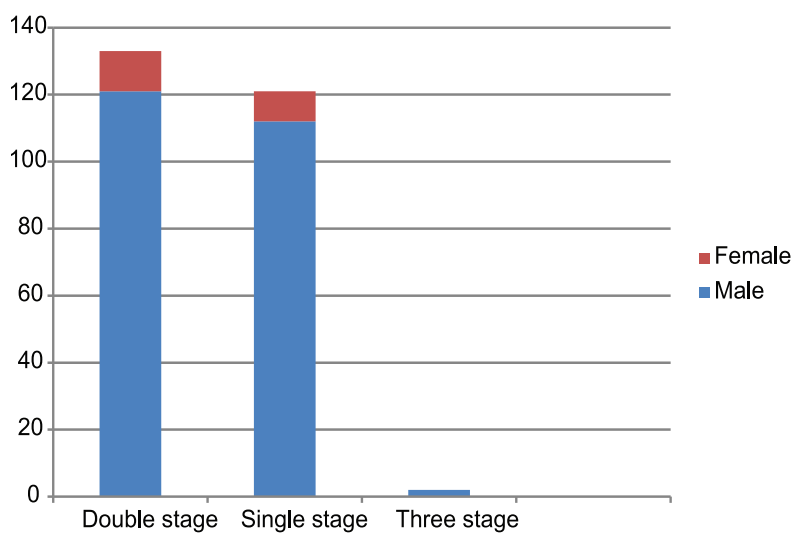

Fig.-1: Chart showing male \& female patients underwent double, single \& three stage

Majority of the patients had minor incontinence; that is flatus and/or loose stool incontinence (table 1).

Table-I

Occurrence of complications of stage procedure

\begin{tabular}{lccc}
\hline Complications & $\begin{array}{c}\text { No. of } \\
\text { patients }\end{array}$ & M & F \\
& & & \\
\hline
\end{tabular}

1. Minor incontinence:

$\begin{array}{llll}\text { a. Flatus incontinence } & 246 & 215 & 31 \\ \text { b. Loose stool } & 239 & 210 & 29 \\ \text { incontinence } & & & \end{array}$

incontinence

2. Major incontinence:

Solid stool incontinence 0

3. Recurrence

4. Bleeding $2 \quad 2 \quad 0$
But they only persisted for an average of 10 to 16 days and subsided spontaneously. None of the patient had any major (solid stool) incontinence. 4 patients had recurrence of fistula on an average of 90 to 183 days after complete healing(table 1.1). 2 patients developed bleeding(table1.1) after single stage procedure and was managed successfully and both of them had underwent two stage procedure of fistulotomy and seton application.

Recurrence occurred in $4(2 \%)$ patients in the form of abscess, automatically burst internally, recurrent fistula. Effective and prompt management was given successfully for all of them.

Table-II

Form of recurrence of fistula complex

\begin{tabular}{lc}
\hline Form of recurrence & No. of patients \\
\hline Abscess & 1 \\
Automatically burst internally & 1 \\
Recurrent fistula & 2 \\
\hline
\end{tabular}

Total healing time after stage procedure was 27 to 65 days with an average of 46 days. Regular dressing and curettage of unhealthy tissue in each visit was ensured for every patient.

Biopsy of every specimen revealed inflammatory necrotic or fibrotic tissue. None of them in this study revealed any granuloma or malignancy.

\section{Discussion}

In this paper we found no major incontinence and $2 \%$ recurrence for stage procedure of complex anal fistula. The data was collected prospectively on a large sample of patients. All the procedures were done by a single surgeon, eliminating the bias which could have occurred with multiple surgeons. However, it is a singlearm study with no comparison group. The majority of the patients were males; this unintentional selection bias was the result of cultural norms in our country as the females prefer to be managed by female surgeons.Different seton materials has been used with different rates of recurrence and incontinence. But whatever the material is, 
recurrence and incontinence rate is mainly dependent on expertise and judgment of the surgeon $^{9}$. So, there are other factors that need to be considered during the selection of the seton. The seton should be durable, cheap, nontoxic/nonallergic, technically easy to tie even in clinic setting, and allows to tight repeatedly without causing pain and without anesthesia (local or general) ${ }^{10}, 11$.The factors implicated in fistula recurrence include the complexity and level of the fistula, the presence or absence of a horseshoe extension, the degree of laterality of the external opening, failure by the surgeon to identify the internal opening at initial surgery, and the overall surgical experience of the operator in complicated proctologic practice ${ }^{12}$.

In our study, we were able to identify the internal opening in all the patients without radiological investigations, and if we correlate this with the low recurrence rate, we can conclude that the most important factor is the surgeon's experience and judgment. Although this seems to be a subjective decision, but it is pragmatic and cost effective in low-income country like ours. Although the cost of MRI is more than the cost of procedure itself, with this cautious technique, we can achieve the best possible results without radiological aids. Chuang-Wei $\mathrm{C}$ et al. ${ }^{13}$ showed in his study that the mean operative time was 42 minutes. The mean duration with the seton in place was 28.7 days. The mean time of the wound healing was 9.3 weeks. Median period of follow-up was 38.6 months. Isbister $\mathrm{WH}$ et al. ${ }^{14}$ concluded in his study by using cutting seton that mean perineal wound healing time was six months. The mean length of follow-up was 1.1 years.In our study mean operative time was 25 minutes, mean duration of seton placement in staged procedure was 4.5 months. Length of follow up was on average of 3 weeks.Looking into the literature, a wide range of incontinence rates is reported after cutting seton treatment. Study conducted by Richie et al. ${ }^{9}$ and Vial et al. ${ }^{15}$ revealed incontinence and recurrence rate ranging from $0 \%$ to $62 \%$ and from $0 \%$ to $16 \%$, respectively, with different materials used as seton. ChuangWei $\mathrm{C}$ et $\mathrm{al}^{13}$ revealed in his study that the recurrence was present in one patient $(0.9 \%)$.
Twenty-seven patients (24.1\%) were noted with continence disorders, including flatus incontinence in 21 patients $(18.6 \%)$ and liquid stool incontinence in 6 patients $(5.4 \%)$. There were no incidents of solid stool incontinence.Isbister $\mathrm{WH}$ et al. ${ }^{14}$ in his study found that after treatment; a total of 17 patients (36.2 percent) were incontinent to gas, 4 to liquid feces (8.5 percent), and 1 to solid feces (2.3 percent). Four patients complained of soiling. Of previously continent patients, 9.5 percent were significantly incontinent to gas, but in addition 21.4 percent were "occasionally" incontinent for gas. Recurrence occurred in one patient. Kamrava A et al. ${ }^{16}$ in his study used adjustable cutting setons consisting of heavy silk ligature with patient-controllable tension. All of the fistulae were treated with at least partial fistulotomy. One $(2 \%)$ patient subsequently developed fecal incontinence, and four $(9 \%)$ developed a recurrent or persistent fistula in the same location. In this study, majority suffered from transient flatus and liquid stool incontinence for an average of 2 weeks, but no solid stool incontinence occurred. Recurrence rate was $2 \%$. Ritchie et al. ${ }^{9}$ have also concluded that there was no relationship between incontinence and the frequency of tightening, type of seton, or classification of fistula. Hence, we further reinforce the importance of surgeon's experience and the use of a seton having additive qualities as stated above.ConclusionThe surgical treatment of anal fistula is a balancing act aimed at eradicating disease, preserving continence, and limiting the morbidity of intervention. The silk seton is safe, ubiquitous, pragmatic, precise, and a costeffective option for the treatment of complex fistulae-in-ano. We, therefore, recommend silk material to treat complex fistulae-in-ano requiring the placement of a seton. It does not carry the disadvantage of recurrent fistula and visits to the operating theater and reduces the morbidity, inconvenience, and cost to the patient.

\section{References:}

1. Blumetti J, Abcarian A, Quinteros F et al. Evolution of treatment of fistula in ano. WorldJ Surg.2012;36:2162-67. 
2. Zbar AP, Khikin M. Should we care about the internal anal sphincter? Dis Colon Rectum. 2012; 55:105-8.

3. Zbar AP, Ramesh J, Beer-Gabel M, Salazar R, Pescatori $\mathrm{M}()$ Conventional cutting vs internal anal sphincter-preservingseton for high trans-sphincteric fistula: a prospective randomizedmanometric and clinical trial. Tech Coloproctol.2003;7:89-94.

4. Kodner IJ, Mazor A, ShemeshEI et al. Endorectal advancement flap repair of rectovaginal and other complicated anorectal fistulas. Surgery.1993.114(4):682-90.

5. Mizrahi N, Wexner SD, Zmora O et al. Endorectal advancement flap: are there predictors of failure? Diseases of the Colon and Rectum.2002;45(12):1616-21.

6. Choen FS, Nicholls RJ. Anal fistula. British Journal of Surgery.1992;79(3):197-205.

7. Pearl RK, Andrews JR, OrsayCP et al. Role of the seton in the management of anorectalfistulas. Diseases of the Colon and Rectum. 1993;36(6):57379.

8. Jorge JMN, Wexner SD.Etiology and management of fecal incontinence. Dis Colon Rectum.1993;36:7797.
9. Ritchie RD, Sackier JM, Hodde JP. Incontinence rates after cutting seton treatment for anal fistula. Colorectal Disease.2009;11(6):564-71.

10. Gurer A, Ozlem N, Gokakin AK et al. A novel material in seton treatment of fistula-in-ano. American Journal of Surgery. 2007;193(6):794-6.

11. Vatansev C, Alabaz O, Tekin A et al. A new seton type for the treatment of anal fistula.Digestive Diseases and Sciences. 2007; 52(8):1920-23.

12. Zbar AP, Ramesh J, Beer-Gabel M et al. Conventional cutting vs. internal anal sphincter-preserving seton for high trans-sphincteric fistula: a prospective randomizedmanometric and clinical trial. Techniques in Coloproctology. 2003;7(2):89-94.

13. Chuang WC, Chang $\mathrm{CW}$, Wen $\mathrm{CH}$ et al. Cutting seton for complex anal fistulas. Surgeon. 2008;6(3): 185-8.

14. Isbister WH, Al-Sanea N. The cutting seton:an experience at King Faisal Specialist Hospital. Dis Colon Rectum. 2001;44(5):722-7.

15. Vial M, Parés D, Pera $M$ et al. Faecal incontinence after seton treatment for anal fistulae with and without surgical division of internal anal sphincter: a systematic review. Colorectal Disease. 2010;12(3): 172-8.

16. Kamrava A, Collins JC. A decade of selective use of adjustable cutting seton combined with fistulotomy for anal fistula. Am Surg. 2011;77(10):1377-80. 